\title{
GMR
}

\section{Rehmannia glutinosa oligosaccharide induces differentiation of bone marrow mesenchymal stem cells into cardiomyocyte-like cells}

\author{
X.H. Wang ${ }^{1}$, H.W. Du ${ }^{2}$, X.H. Guo ${ }^{3}$, S.W. Wang ${ }^{3}$, R.B. Zhou ${ }^{1}$, Y. Li ${ }^{3}$, \\ Z.B. $\mathrm{Li}^{3}$, Y.S. Zhao ${ }^{3}$ and Q.L. $\mathrm{Zhu}^{3}$ \\ ${ }^{1}$ Department of Emergency, Military General Hospital of Beijing PLA, \\ Beijing, China \\ ${ }^{2}$ Department of Medical, Military General Hospital of Beijing PLA, \\ Beijing, China \\ ${ }^{3}$ Institute of Geriatric Cardiology, General Hospital of PLA, Beijing, China \\ Corresponding author: R.B. Zhou \\ E-mail: rongbinzhoucn@126.com
}

Genet. Mol. Res. 15 (4): gmr15047795

Received October 7, 2016

Accepted August 18, 2016

Published October 17, 2016

DOI http://dx.doi.org/10.4238/gmr15047795

Copyright (C) 2016 The Authors. This is an open-access article distributed under the terms of the Creative Commons Attribution ShareAlike (CC BY-SA) 4.0 License.

\begin{abstract}
The aim of this study was to observe the effect of Rehmannia glutinosa oligosaccharide (RGO) on differentiation of bone marrow mesenchymal stem cells (MSCs) into cardiomyocytelike cells . Rat MSCs were isolated, treated, and grouped as follows: RGO treatment group, 5-azacytidine (5-aza) treatment group, RGO +5 -aza treatment group, and control group. Following a four-week induction period, cardiac troponin I (cTnI) levels in MSCs were quantified by chemiluminescence, and the levels of myocardial enzymes creatine kinase (CK) and creatine kinase isoenzyme-MB (CK-MB) were measured using a dry chemistry analyzer. The cTnIand connexin 43 (Cx43)-positive MSC population was identified by
\end{abstract}

Genetics and Molecular Research 15 (4): gmr15047795 
immunofluorescence, and expression levels of cTnI and $\mathrm{Cx} 43$ were analyzed by western blots. Following induction, cTnI, CK, and CK-MB levels were significantly higher in the $\mathrm{RGO}+5$-aza group as compared with the RGO and 5-aza groups $(\mathrm{P}<0.05)$. In addition, fluorescence intensity of cTnI and $\mathrm{Cx} 43$ was higher in the $\mathrm{RGO}+5$-aza group as compared with the RGO and 5-aza groups. No cTnI- or Cx43-positive cells were detected in the control group. Western blot analysis further confirmed that $\mathrm{cTnI}$ and $\mathrm{Cx} 43$ were not expressed in the control group, while cTnI and $\mathrm{Cx} 43$ was higher in the RGO +5 -aza group than in the RGO and 5-aza groups. These results suggest that MSCs can be induced by RGO to differentiate into cardiomyocyte-like cells in vitro, and that RGO in combination with 5-aza enhance differentiation of MSCs.

Key words: Rehmannia glutinosa oligosaccharide; Mesenchymal stem cells; Cardiomyocyte-like cells;

Cell differentiation

\section{INTRODUCTION}

In recent years, stem cell transplantation in the heart has become a new research focus (Dey et al., 2010). Bone marrow mesenchymal stem cells (MSCs) have been commonly used as donor stem cells for transplantation as they can differentiate into diverse cell types, including cardiomyocyte-like cells and vascular endothelial cells (Antonitsis et al., 2008; Yue et al., 2008). 5-Azacytidine (5-aza) is often used to induce differentiation of MSCs into myocardial cells; however, 5-aza is associated with various adverse effects as an antitumor drug (Borodovsky et al., 2013). A number of studies focusing on traditional Chinese medicine extracts found that Rehmannia glutinosa oligosaccharide (RGO), extracted from R. glutinosa, could promote the differentiation of MSCs into skeletal muscle myoblasts in vitro (Chen et al., 2015). In addition, RGO has also been shown to regulate immunity, protect the myocardium, as well as exert antidiabetic and antitumor effects (Lai et al., 2012). However, there has been little research comparing the effects of 5-aza and RGO on cell differentiation. More robust MSC differentiation can likely be induced by combining 5-aza and RGO treatments than by either treatment alone. The aim of this study therefore was to compare the effects of 5-aza, $\mathrm{RGO}$, and a combination of both treatments on MSC differentiation.

\section{MATERIAL AND METHODS}

\section{Experimental animals}

Seven-week-old purebred Wistar rats (clean grade, male, and average body weight: $180 \pm 10 \mathrm{~g}$ ) were provided by the Experimental Animal Center of the General Hospital of PLA (Beijing; certificate No. 20050013). This study was carried out in strict accordance with recommendations from the Guide for the Care and Use of Laboratory Animals of the National Institutes of Health. The experimental protocol was reviewed and approved by the Institutional Animal Care and Use Committee of Military General Hospital of Beijing PLA.

Genetics and Molecular Research 15 (4): gmr15047795 
Three individual experiments were performed in triplicates using three samples. The rats were divided into four experimental groups consisting of 12 animals in each cohort. Four indexes were observed: morphological characteristics of MSCs, the effect of RGOs on biochemical markers of heart muscle MSCs, identification of MSCs following their induction, and western blot analysis after MSC induction.

\section{Isolation and culture of cardiomyocytes from neonatal rats}

The cardiac apex of two-day-old male and female Wistar rats was dissected via thoracotomy under sterile conditions. The tissue was washed three times with pre-cooled D-Hank's solution, cut into $1-\mathrm{mm}^{3}$ cubes, and digested with $0.0625 \%$ trypsin at $37^{\circ} \mathrm{C}$. Following precipitation, the supernatant was added to an equal amount of DMEM culture containing $10 \%$ FBS. The solution was gently pipetted to yield a single cell suspension, and was followed by centrifugation at $1000 \mathrm{rpm}$ for $10 \mathrm{~min}$. The cell suspension was incubated for 90 min at $37^{\circ} \mathrm{C}$ with $5 \% \mathrm{CO}_{2}$. Differential wall-adhesion separation method was then used to absorb the cell suspension, and cell concentration was adjusted to $5.0 \times 10^{5}$ cells $/ \mathrm{mL}$. Cells were seeded in culture plates, and medium was changed after $24 \mathrm{~h}$. Subsequent media replacements were performed every other day.

\section{Isolation and culture of MSCs}

Rats were anesthetized by intraperitoneal administration of $20 \%$ urethane, and were then dipped in $75 \%$ ethanol for $5 \mathrm{~min}$. Under sterile conditions, the femoral were quickly isolated and rinsed with PBS, and the two ends of the bone were cut. Bone marrow was rinsed out with $5 \mathrm{~mL}$ low glucose DMEM solution (Thermo Fisher, Waltham, USA) containing 10\% FBS (GE Healthcare, Logan, USA). Bone marrow cell suspension was collected, filtered with a 4-gauge needle, and fully dispersed. Prepared cell suspensions were added to the culture bottle, and were incubated at $37^{\circ} \mathrm{C}$ and $5 \% \mathrm{CO}_{2}$. After $24 \mathrm{~h}$, the medium was changed for the first time, and cell growth was observed under a phase contrast microscope.

\section{Passage and purification of MSCs}

As primary cell cultures reached $100 \%$ confluency, cells were passaged. Cell digestion was carried out with $0.125 \%$ trypsin (Thermo Fisher, Waltham, MA, USA), and was terminated with culture liquid. Adherent cells were detached with repeated pipetting, and were passaged at 1:2 dilution. The newly passaged cells were labeled as P1. Cell growth was observed each day until $100 \%$ confluency was reached, at which point the above procedure was repeated up to the eighth generation.

\section{Induction and differentiation of MSCs}

Eighth generation MSCs were added to 6-well plates with preset glass bottoms, and were cultured for three days. Cells were treated and grouped as follows: RGO (PLA Pharmacological Experiments Base, General Hospital of Lanzhou Area Command of PLA, Lanzhou, China) treatment group (final concentration $=100 \mu \mathrm{g} / \mathrm{mL}$ ), 5-aza (Sigma-Aldrich, St. Louis, MO, USA) treatment group (final concentration $=10 \mu \mathrm{M}$ ), RGO +5 -aza group 
(final concentration $=100 \mu \mathrm{g} / \mathrm{mL}, 10 \mu \mathrm{M}$, respectively), and control group (PBS). For each group, we treated 12 wells for $24 \mathrm{~h}$, after which the medium was replaced. We continued to culture these cells and observed changes in cell morphology for four consecutive weeks; medium was changed every three days.

\section{Determination of myocardial biochemical markers}

Following a four-week induction culture period, cells on 6-well plates from each group were washed twice with cold PBS $(3 \mathrm{~mL})$, and $0.5 \mathrm{~mL}$ cell lysis buffer was added. Cells were scraped off with a cell scraper and by repeated pipetting, collected in 1.5-mL Eppendorf tubes, and centrifuged at $12,000 \mathrm{rpm}$ for $15 \mathrm{~min}$ at $4^{\circ} \mathrm{C}$. After centrifugation, the supernatant was transferred to another Eppendorf tube. Cardiac troponin I (cTnI) (Santa Cruz, Dallas, TX, USA) expression was detected by chemiluminescence; the myocardial enzymes, creatine kinase (CK) and CK isoenzyme-MB (CK-MB), were detected using a dry chemistry analyzer.

\section{Immunofluorescence}

Four weeks following induction and culture, cells were permeabilized with $0.3 \%$ Triton X-100, fixed in 4\% paraformaldehyde at room temperature for $20 \mathrm{~min}$, and washed three times with PBS for a total of $15 \mathrm{~min}$. Anti-cTnI and anti-connexin 43 (Cx43)antibodies were added; PBS was used as the negative control. Samples labeled with primary antibodies were placed in a wet box and incubated overnight at $4^{\circ} \mathrm{C}$. They were washed three times with PBS for a total of 15 min the next day. FITC-labeled goat anti-rabbit secondary antibody (ZSGB-BIO, Beijing, China) was then added, and the samples were incubated for $1 \mathrm{~h}$ at $37^{\circ} \mathrm{C}$ in a wet box. Cells were washed three times with PBS for a total of $15 \mathrm{~min}$, and were labeled with DAPI $(25 \mu \mathrm{g} / \mathrm{mL})$ for $10 \mathrm{~min}$. Lastly, cells were washed (PBS, three times), sealed with $50 \%$ buffered glycerol, and imaged using a confocal laser microscope (LEXTOLS3100).

\section{Western blot}

Following induction and a four-week culture, cells were washed with PBS and lysed. The lysate was placed on ice for $30 \mathrm{~min}$ and centrifuged at $12,000 \mathrm{rpm}$ for $30 \mathrm{~min}$ at $4^{\circ} \mathrm{C}$. The supernatant was transferred to a new Eppendorf tube, and total protein was quantified by the Bradford method. Using myocardial cells of neonatal rats as a positive control, protein from these cells was extracted and quantified according to the Bradford method. SDS protein electrophoresis buffer $(6 \mathrm{X})$ was added to sample aliquots, which were then heated for $5 \mathrm{~min}$ at $100^{\circ} \mathrm{C}$. Samples $(40 \mathrm{mg})$ were loaded onto SDS-PAGE gels and electrophoresed. Proteins were transferred onto polyvinylidene fluoride membranes (GE Healthcare, Pittsburgh, PA, USA) for $60 \mathrm{~min}(150 \mathrm{~mA})$ and blocked with $15 \mathrm{~mL}$ TBST at $4^{\circ} \mathrm{C}$ overnight. The primary antibodies, anti-cTnI and anti-Cx43 (Boster, Wuhan, China), were added at concentrations of 1:2,000 and 1:1,000, respectively. Blots were washed five times (25 $\mathrm{min}$ in total), and the secondary antibody was added at a concentration of 1:2,000. The membrane was gently shaken at room temperature for $1 \mathrm{~h}$. Lastly, the membrane was washed five times ( $25 \mathrm{~min}$ in total), and was imaged via chemiluminescence (KPL, Gaithersburg, MD, USA). Protein levels were quantified using semi-quantitative analysis.

Genetics and Molecular Research 15 (4): gmr15047795 


\section{Statistical analysis}

Analysis was performed with the SPSS 13.0 statistical software. Data are reported as means $\pm \mathrm{SD}$. Differences between groups were compared using single-factor analysis of variance. Statistical significance was defined as $\mathrm{P}<0.05$.

\section{RESULTS}

\section{Morphological characteristics of MSCs}

Following a 24-h culture period, the majority of primary MSCs had adhered to the plate. Three to four days later, colony growth was observed, and cells exhibited short and fusiform morphology. Cells were 100\% confluent after 7-10 days of culture. In addition, cells were completely adherent $24 \mathrm{~h}$ following passaging, and were mostly fusiform or fibrous in morphology. An increase in cell volume was observed $72 \mathrm{~h}$ following passaging.

\section{Effect of RGO on myocardial biochemical markers in MSCs}

After RGO, 5-aza, or RGO + 5-aza treatments, the expressions of cTnI, CK, and CK-MB significantly increased as compared to that of the control $(\mathrm{P}<0.05)$. There was no significant difference in the levels of cTnI, CK, and CK-MB between the RGO and the 5-aza group $(\mathrm{P}>0.05)$. However, $\mathrm{CK}$ and $\mathrm{CK}-\mathrm{MB}$ levels were significantly higher in the RGO + 5 -aza group as compared with the RGO- and 5-aza- only groups $(\mathrm{P}<0.05)$. While cTnI level slightly increased in the RGO + 5-aza group as compared to the level in the RGO and 5-aza groups, this difference was not statistically significant $(\mathrm{P}>0.05$, Table 1$)$.

\section{Table 1. Effect of RGOs on the expression of cardiac MSC biochemical markers.}

\begin{tabular}{l|c|c|c}
\hline Groups & CtnI $(\mathrm{ng} / \mathrm{mL})$ & CK $(\mathrm{U} / \mathrm{L})$ & CK-MB (U/L) \\
\hline RGOs & $0.17 \pm 0.03^{*}$ & $96.33 \pm 8.11^{* \#}$ & $74.7 \pm 6.40^{* \#}$ \\
\hline 5-aza & $0.18 \pm 0.02^{*}$ & $104.4 \pm 4.07^{* \#}$ & $91.93 \pm 6.44^{* \#}$ \\
\hline RGOs+5-aza & $0.24 \pm 0.04^{*}$ & $115.7 \pm 4.20^{*}$ & $0.15^{*}$ \\
\hline Control & $0.013 \pm 0.006$ & $0.83 \pm 0.15$ & 0 \\
\hline
\end{tabular}

$* \mathrm{P}<0.05$ as compared with control group; ${ }^{\mathrm{P}}<0.05$ as compared with the 5 -aza + RGOs group. All data are reported as means $\pm \mathrm{SD}(\mathrm{N}=3)$.

\section{Immunofluorescence of induced MSCs}

No cTnI- or Cx43-positive cells were observed in the control group, in which MSCs were not induced to differentiate; both cTnI- and Cx43-positive cells were observed in the RGO, 5-aza, and RGO + 5-aza groups. Fluorescent signals were found to be higher in the $\mathrm{RGO}+5$-aza group than in the RGO and 5-aza groups (Figure 1).

\section{Western blot of induced MSCs}

Expressions of cTnI and Cx43 were not observed in control MSCs; the expressions of cTnI and $\mathrm{Cx} 43$ were the highest in the positive control group (normal neonatal rat cardiac

Genetics and Molecular Research 15 (4): gmr15047795 
myocytes). MSCs in the RGO, 5-aza, and RGO + 5-aza groups expressed both cTnI and $\mathrm{Cx} 43$. Similar to previous results, expressions of cTnI and $\mathrm{Cx} 43$ were higher in the $\mathrm{RGO}+5$-aza group than in the RGO- and 5-aza-only groups (Figure 2).

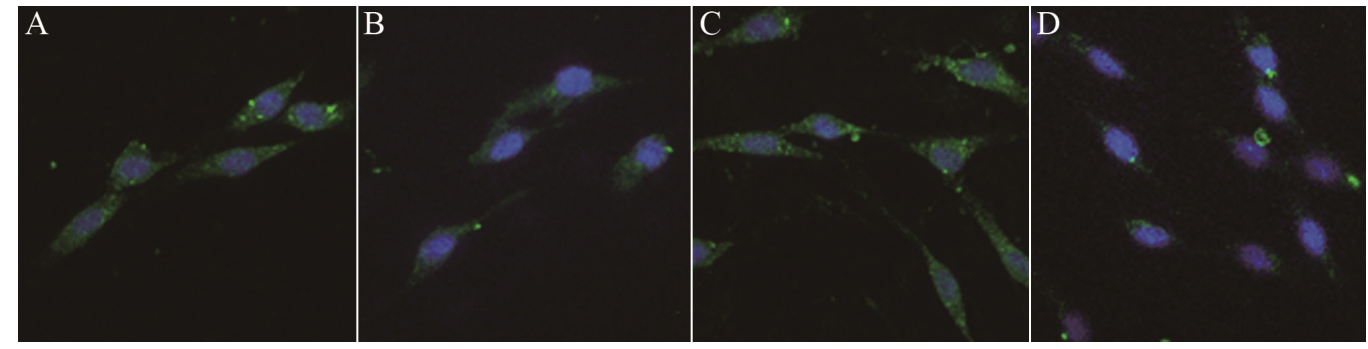

Figure 1. Immunofluorescence identification of induced MSCs (1000X). A. RGO group; B. 5-aza group; C. RGO +5-aza group; D. blank control group.

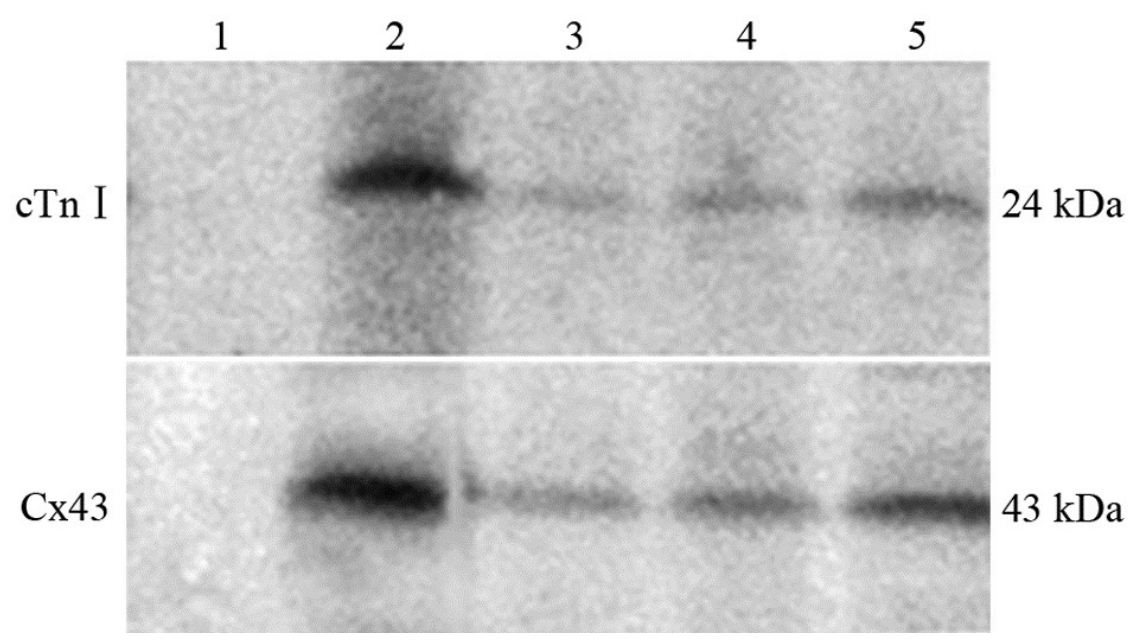

Figure 2. Expression of myocardium-specific proteins detected by western blotting. Lane $1=$ blank control group; lane 2 = positive control group; lane $3=\mathrm{RGO}$ group; lane $4=5$-aza group; lane $5=\mathrm{RGO}+5$-aza group.

\section{DISCUSSION}

Injuries to the myocardium can induce myocardial remodeling, which is associated with cellular necrosis that may eventually result in heart failure. Current treatments for heart failure are limited, and cell transplantation has the potential to represent a new form of treatment. MSCs are multipotent cells that have the ability to differentiate into diverse cell types. In addition, they secrete a variety of angiogenic, anti-apoptosis, and mitogenic factors via paracrine effects (Nagaya et al., 2005; Nagaya and Kitamura, 2008). It has been shown that MSCs are able to maintain their multipotency in primary cultures as well as following cell 
passaging. For example, Deans and Moseley (2000) reported that MSCs could maintain their multipotency in vitro even after 40 generations.

Recent data show that MSCs also have immunomodulatory functions (Uccelli et al., 2006; Ramasamy et al., 2008), mainly through the release of soluble cytokines such as prostaglandin E2 (Manferdini et al., 2013), transforming growth factor $\beta$, human leukocyte antigen G5, and matrix metalloproteinase (De Miguel et al., 2012). Following transplantation, upregulation of $\mathrm{CD} 4^{+} / \mathrm{CD} 25^{+}$regulatory $\mathrm{T}$ cells play a significant role in inducing immune tolerance of the graft (Ge et al., 2013). This can be achieved by modulating T cell proliferation as well as by regulating the type and quantity of T cell secretions. At present, MSCs provide a promising option (Selem et al., 2013) in the treatment of dilated cardiomyopathy. In rats with myocardial infarctions, it has been shown that the earlier the MSC transplantation was performed, the better the recovery of heart function was. Analysis of reduction in ventricular remodeling demonstrated that the effect of MSC on heart transplantation was dose dependent (Richardson et al., 2013). Due to their therapeutic potentials, MSCs are one of the most widely studied types of adult stem cells at present.

RGO is a popular traditional Chinese medicine extracted from R. glutinosa (Park et al., 2005). RGO can inhibit the progression of experimental thrombosis and atherosclerosis, and can act as an antioxidant (Park et al., 2006; Yu et al., 2006a,b). Previous studies have shown that RGO extract improves glucose metabolism, and can prevent and ameliorate pathologies arising from diabetes (Yokozawa et al., 2004). Other studies have also demonstrated that it improves insulin resistance of HepG2 cells. A more recent study found that it promotes adipose-derived MSC proliferation through VEGF and HGF paracrine signaling, which may reduce $\mathrm{H}_{2} \mathrm{O}_{2}$-induced MSC apoptosis (Zhang et al., 2012). Preliminary results from our lab suggested that RGO promotes the proliferation of bone marrow MSCs in vitro at an optimal concentration of $100 \mu \mathrm{g} / \mathrm{mL}$. In this study, we found that the levels of cTnI, CK, and CK-MB were elevated in MSC lysates treated with RGO. Moreover, MSCs in the RGO + 5-aza group exhibited higher levels of cTnI, CK, and $\mathrm{CK}-\mathrm{MB}$ as compared with the RGO and 5-aza groups. Immunofluorescence results indicated that following induction, MSCs expressed differential levels of cTnI and Cx43; the expression was highest in the RGO + 5-aza group. Western blot results confirmed the elevated cTnI and $\mathrm{Cx} 43$ expressions following induction, and showed that $\mathrm{cTnI}$ and $\mathrm{Cx} 43$ levels were the highest in the RGO + 5-aza group. Our study suggested that MSCs are able to adopt the characteristics of cardiac muscle cells following induction. The ability of RGO and 5-aza to induce cardiomyogenic transformation was confirmed at the protein level. MSCs induced by a combination of RGO and 5 -aza exhibited the highest expression of cardiac-specific proteins, suggesting that RGO and 5 -aza act synergistically to induce more robust differentiation of MSCs into cardiomyocyte-like cells. 5-aza is a DNA methylation inhibitor; it has been widely used to differentiate MSCs into cardiomyocyte-like cells, and the optimal induction dose was determined to be $10 \mu \mathrm{M}$ (Makino et al., 1999; Tomita et al., 1999). The mechanisms underlying 5-aza induction may be associated with reduction of DNA methylation in cells. However, 5-aza is potentially toxic and may induce cell apoptosis. Our studies demonstrated that RGO could induce differentiation of MSCs into cardiomyocyte-like cells, however, the mechanisms underlying this process are still unclear. A previous study showed that RGO could improve myocardial function by scavenging oxygen free radicals, and can enhance the proliferation of hematopoietic progenitor cells by promoting the production of colony-stimulating factor. It remains to be confirmed whether differentiation of MSCs into cardiomyocyte-like cells by RGO is due to its ability to induce secretion of certain regulatory factors by MSCs.

Genetics and Molecular Research 15 (4): gmr15047795 
This study demonstrated that RGO could induce MSCs to differentiate into cardiomyocytes, suggesting that it may be used as a supplemental therapy to MSC transplantation in the treatment of cardiovascular diseases. To conclude, we have provided a novel paradigm for the treatment of diseases that combines traditional Chinese medicine with cell engineering.

\section{Conflicts of interest}

The authors declare no conflict of interest.

\section{REFERENCES}

Antonitsis P, Ioannidou-Papagiannaki E, Kaidoglou A, Charokopos N, et al. (2008). Cardiomyogenic potential of human adult bone marrow mesenchymal stem cells in vitro. Thorac. Cardiovasc. Surg. 56: 77-82. http://dx.doi. org $/ 10.1055 / \mathrm{s}-2007-989328$

Borodovsky A, Salmasi V, Turcan S, Fabius AW, et al. (2013). 5-azacytidine reduces methylation, promotes differentiation and induces tumor regression in a patient-derived IDH1 mutant glioma xenograft. Oncotarget 4: 1737-1747. http:// dx.doi.org/10.18632/oncotarget.1408

Chen XY, Wang RF and Liu B (2015). An update on oligosaccharides and their esters from traditional chinese medicines: chemical structures and biological activities. Evid. Based Complement. Alternat. Med. 2015: 512675. http://dx.doi. org $/ 10.1155 / 2015 / 512675$

De Miguel MP, Fuentes-Julián S, Blázquez-Martínez A, Pascual CY, et al. (2012). Immunosuppressive properties of mesenchymal stem cells: advances and applications. Curr. Mol. Med. 12: 574-591. http://dx.doi. org/10.2174/156652412800619950

Deans RJ and Moseley AB (2000). Mesenchymal stem cells: biology and potential clinical uses. Exp. Hematol. 28: 875884. http://dx.doi.org/10.1016/S0301-472X(00)00482-3

Dey BR, Chung SS, Spitzer TR, Zheng H, et al. (2010). Cardiac transplantation followed by dose-intensive melphalan and autologous stem-cell transplantation for light chain amyloidosis and heart failure. Transplantation 90: 905-911. http://dx.doi.org/10.1097/TP.0b013e3181f10edb

Ge X, Bai C, Yang J, Lou G, et al. (2013). Intratracheal transplantation of bone marrow-derived mesenchymal stem cells reduced airway inflammation and up-regulated $\mathrm{CD} 4{ }^{+} \mathrm{CD} 25^{+}$regulatory $\mathrm{T}$ cells in asthmatic mouse. Cell Biol. Int. 37: 675-686. http://dx.doi.org/10.1002/cbin.10084

Lai PK, To MH, Lau KM, Liu CL, et al. (2012). Stachyose: One of the active fibroblast-proliferating components in the root of Rehmanniae Radix (dì huáng). J. Tradit. Complement. Med. 2: 227-234. http://dx.doi.org/10.1016/S2225$\underline{4110(16) 30104-3}$

Makino S, Fukuda K, Miyoshi S, Konishi F, et al. (1999). Cardiomyocytes can be generated from marrow stromal cells in vitro. J. Clin. Invest. 103: 697-705. http://dx.doi.org/10.1172/JCI5298

Manferdini C, Maumus M, Gabusi E, Piacentini A, et al. (2013). Adipose-derived mesenchymal stem cells exert antiinflammatory effects on chondrocytes and synoviocytes from osteoarthritis patients through prostaglandin E2. Arthritis Rheum. 65: 1271-1281. http://dx.doi.org/10.1002/art.37908

Nagaya N and Kitamura S (2008). Regenerative medicine for heart failure. Nihon Rinsho 66: 978-983.

Nagaya N, Kangawa K, Itoh T, Iwase T, et al. (2005). Transplantation of mesenchymal stem cells improves cardiac function in a rat model of dilated cardiomyopathy. Circulation 112: 1128-1135. http://dx.doi.org/10.1161/ CIRCULATIONAHA.104.500447

Park C, So HS, Kim SJ, Youn MJ, et al. (2006). Samul extract protects against the H2O2-induced apoptosis of H9c2 cardiomyoblasts via activation of extracellular regulated kinases (Erk) 1/2. Am. J. Chin. Med. 34: 695-706. http:// dx.doi.org/10.1142/S0192415X06004211

Park WH, Hong MY, Chung KH, Kim HM, et al. (2005). Effects of traditional herbal medicine, Hwaotang, on atherosclerosis using the spontaneous familial hypercholesterolemia model, Kurosawa and Kusanagi-hypercholesterolemic rabbits and the venous thrombosis rats. Phytother. Res. 19: 846-853. http://dx.doi.org/10.1002/ptr.1700

Ramasamy R, Tong CK, Seow HF, Vidyadaran S, et al. (2008). The immunosuppressive effects of human bone marrowderived mesenchymal stem cells target $\mathrm{T}$ cell proliferation but not its effector function. Cell. Immunol. 251: 131-136. http://dx.doi.org/10.1016/j.cellimm.2008.04.009

Genetics and Molecular Research 15 (4): gmr15047795 
Richardson JD, Bertaso AG, Psaltis PJ, Frost L, et al. (2013). Impact of timing and dose of mesenchymal stromal cell therapy in a preclinical model of acute myocardial infarction. J. Card. Fail. 19: 342-353. http://dx.doi.org/10.1016/j. cardfail.2013.03.011

Selem SM, Kaushal S and Hare JM (2013). Stem cell therapy for pediatric dilated cardiomyopathy. Curr. Cardiol. Rep. 15: 369. http://dx.doi.org/10.1007/s11886-013-0369-z

Tomita S, Li RK, Weisel RD, Mickle DA, et al. (1999). Autologous transplantation of bone marrow cells improves damaged heart function. Circulation 100 (Suppl): II247-II256. http://dx.doi.org/10.1161/01.CIR.100.suppl 2.II-247

Uccelli A, Moretta L and Pistoia V (2006). Immunoregulatory function of mesenchymal stem cells. Eur. J. Immunol. 36: 2566-2573. http://dx.doi.org/10.1002/eji.200636416

Yokozawa T, Kim HY and Yamabe N (2004). Amelioration of diabetic nephropathy by dried Rehmanniae Radix (Di Huang) extract. Am. J. Chin. Med. 32: 829-839. http://dx.doi.org/10.1142/S0192415X04002442

Yu HH, Kim YH, Jung SY, Shin MK, et al. (2006a). Rehmannia glutinosa activates intracellular antioxidant enzyme systems in mouse auditory cells. Am. J. Chin. Med. 34: 1083-1093. http://dx.doi.org/10.1142/S0192415X06004545

Yu HH, Seo SJ, Kim YH, Lee HY, et al. (2006b). Protective effect of Rehmannia glutinosa on the cisplatin-induced damage of HEI-OC1 auditory cells through scavenging free radicals. J. Ethnopharmacol. 107: 383-388. http://dx.doi. org/10.1016/j.jep.2006.03.024

Yue WM, Liu W, Bi YW, He XP, et al. (2008). Mesenchymal stem cells differentiate into an endothelial phenotype, reduce neointimal formation, and enhance endothelial function in a rat vein grafting model. Stem Cells Dev. 17: 785-793. http://dx.doi.org/10.1089/scd.2007.0243

Zhang Y, Wang Y, Wang L, Zhang Y, et al. (2012). Effects of Rehmannia glutinosa oligosaccharide on human adiposederived mesenchymal stem cells in vitro. Life Sci. 91: 1323-1327. http://dx.doi.org/10.1016/j.lfs.2012.10.015

Genetics and Molecular Research 15 (4): gmr15047795 